\title{
To Buy or to Outsource: Either Way, Your Equipment Manufacturer Can Help
}

\author{
Marie C. Vicéns
}

ASPEX, an FEI Company, 175 Sheffield Drive, Delmont, PA 15626

marie.vicens@fei.com

\section{Introduction}

Many industrial companies do not have the expertise, experience, or in-house analytical instrumentation to conduct routine laboratory testing. As such, selecting a contract analytical services provider is a common task. Outsourcing is a cost-effective alternative that can allow companies to increase analytical information available for timely decisions regarding product development and production (see Figure 1).

To find the right contract services provider, the contracting company should use a process-based approach: the company should determine its primary outsourcing needs and the amount of time and money available for the investment. Executives should be engaged in the decision-making process to identify and approve the contract requirements.

If the decision is to outsource, the simple choice is an equipment manufacturer that has laboratory facilities and testing capabilities available for contract. Many equipment manufacturers now have laboratory facilities that use the same instruments that they offer for sale (see Figure 2); they have often conducted analytical testing as a means to improve their product offerings and to provide demonstration services to prospective equipment purchasers. However, with today's

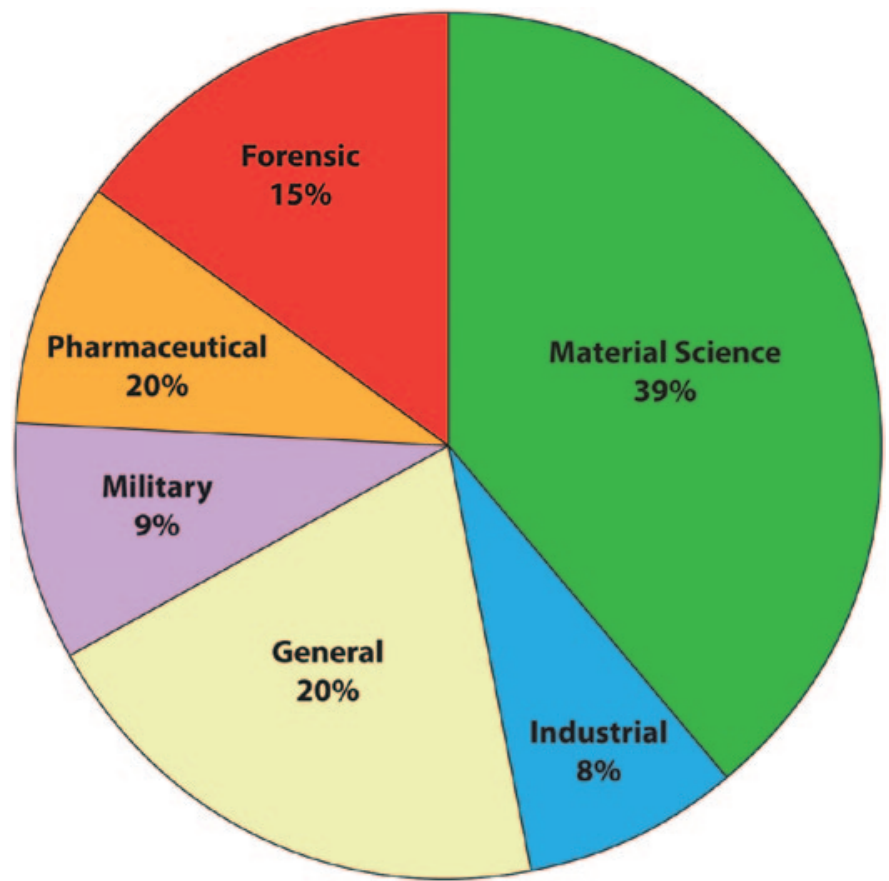

Figure 1: Distribution of industries requesting solutions from an electron microscopy manufacturer with contract services facilities located in Pennsylvania. These companies did not have the technological resources in-house but had an immediate need to obtain information for timely decisions regarding their products' development and quality.

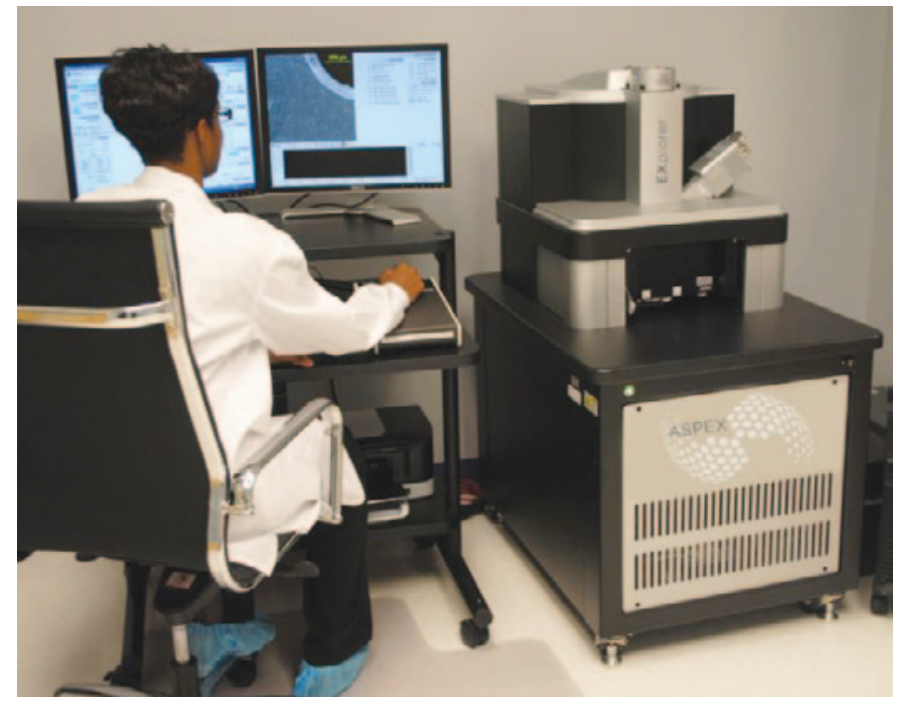

Figure 2: Laboratory technician using scanning electron microscope with energy dispersive spectrometer available for purchase by the customer. Contracted experts at the manufacturer's laboratory can analyze data quickly and efficiently using advanced knowledge of cutting-edge technology.

increasing demand for outsourcing of testing services, many manufacturers have taken the necessary steps to become full-fledged contract analytical laboratories [1].

This article discusses the use of equipment manufacturers as providers of contract analytical testing services. The article also highlights the advantages of developing a relationship with a given equipment manufacturer before purchasing an instrument.

\section{When Should Outsourcing Be Considered?}

A company with one or more of the following issues is an ideal candidate to consider contracting with an established equipment manufacturing company:

- a limited budget for an expensive equipment purchase;

- short-term project needs that do not require the purchase of capital equipment;

- long purchase approval processes, but an immediate solution is needed;

- a need to find a solution for technical or quality challenges, but uncertainty about which analytical instrument should be used;

- a need to understand and test the instrument before committing to purchase; and

- ownership of instruments that have not been able to satisfy needs.

\section{Finding Analytical Services Providers}

The most common approach to finding a contract services provider is to search the web for contact information and 


\section{The SPI Supplies Family}

of Instruments

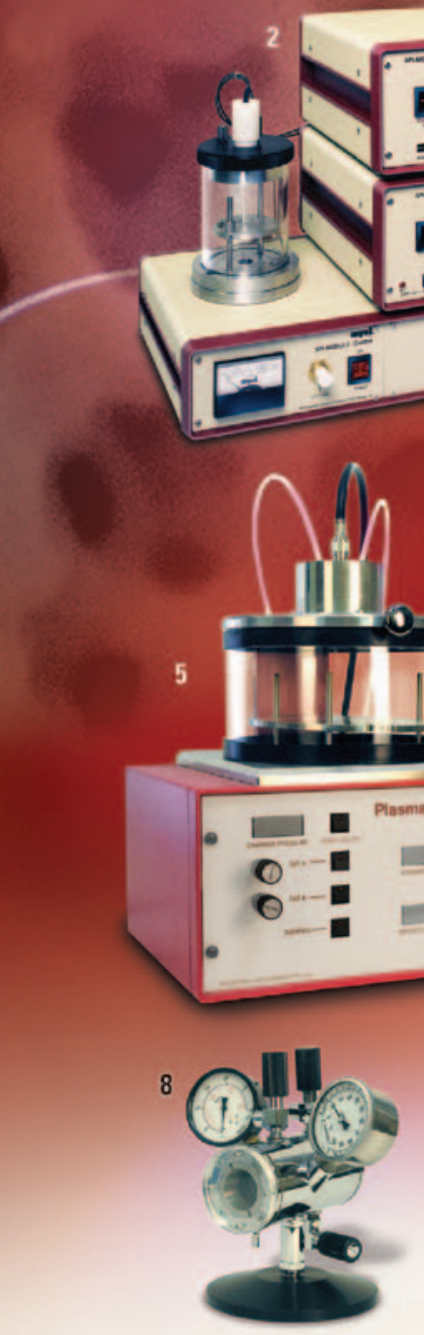

Your results will never be better than

your sample preparation. See how SPI Supplies can help you deliver the highest quality results for all your SEM/EDS, TEM and FESEM applications.

\section{Excellence in sample preparation} just a click away... 2spi.com

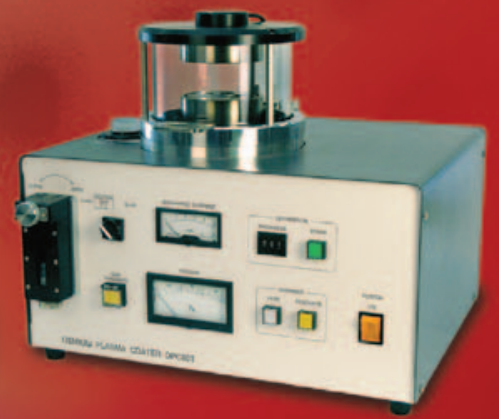

1. Osmium Plasma Coaters for FESEM Applications

2. SPI-MODULE ${ }^{\mathrm{m}}$

Sputter/Carbon Coater Module

3. Gentle Mill'm

Ion Milling System

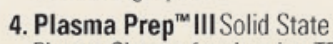

Plasma Cleaner for cleaning TEM holders
5. Plasma Prep ${ }^{\text {'m }} X$

Parallel Plate Plasma Etcher

6. Plasma Prep ${ }^{\text {tm }}$ III Plasma Etcher with PPIII Process Controller

7. Vacu Prep"'II

Turbo Pump Evaporation System

8. SPI-DRY'm

Critical Point Dryer

9. Precision Spin Coater Spin coater

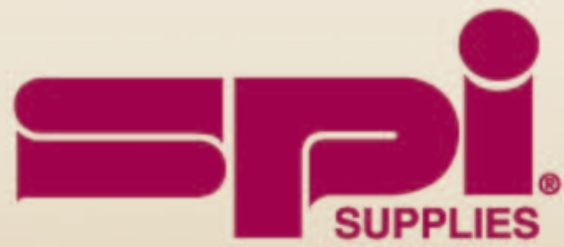

SPI Supplies Division of STRUCTURE PROBE, Inc. 
technical content-data sheets, case studies, application notes, etc.-that can be used to compile a list of service providers. Attending trade shows, reviewing print advertisements in trade publications, and looking through buyers' guides are also traditional sources used during a company's preliminary screening process.

Another option is to look right in your own backyard. In other words, consider using your equipment manufacturer as a contract analytical services provider. By partnering with a manufacturer that has the capability to provide quality analytical testing services, companies gain the opportunity to reduce overhead on specialized equipment.

A partnership with an equipment manufacturer can begin as a short-term strategic option in response to an increased demand for testing, a need to reduce sample backlogs, or to quickly conduct a product quality investigation requiring an immediate answer [2]. In many instances, equipment manufacturers have leasing options that allow a company temporary acquisition of the equipment needed to resolve immediate testing needs. However, this option can take several weeks to install the instrument and train the operator.

\section{Evaluation of Service Providers}

When evaluating an equipment manufacturer as a potential contract services provider, it is important to remember that not every testing facility has the necessary standard procedures and quality assurance systems in place to perform the type of testing required. Often, vendors conduct demonstration testing services to support equipment sales, but these services are not necessarily regulated or documented, nor are their methods validated. Reports submitted by non-regulated testing facilities frequently come with disclaimers indicating that the data collected is not indicative of the properties from the material tested.

During the first phone call or meeting with a prospective analytical services contractor, the contracting company should make sure that quality policies and standard operating procedures are in place. An audit should be performed before signing any contracts, especially for a long-term project. Also, quality manuals and certifications should be available upon request.

\section{Short-Term and Strategic Outsourcing}

New analytical instrumentation can be evaluated during a short-term outsourcing project. Short-term outsourcing is a flexible solution used as a response to a sudden demand for analytical testing. This can be the case when one sample needs to be tested as part of a quality investigation or if a small batch of samples needs to be processed to evaluate an ongoing manufacturing process.

For service providers, short-term outsourcing can lead to an increased number of smaller value projects, and, if successful, it might result in a long-term project. Short-term contract work should be highly straightforward because there is neither enough time nor money to develop and implement a more customized solution.

Strategic outsourcing leads to a long-term relationship between the contracting company and the contracted equipment vendor providing services. Therefore, the relationship must be based on a mutual understanding: the service provider must understand the problem that needs to be resolved, and the contracting company must understand the instrumentation and services available, as well as how this technology will be used to solve their problem. These questions can be answered during the initial phase of problem definition and evaluation.

When a project is in its first stages, the contracting company's product development team is responsible for identifying the proper technology and instrumentation needed to perform all necessary tests before a product can be released commercially. Ease of use, analysis throughput, data interpretation, amount of statistical information, equipment size, laboratory space, and implementation costs are some of the factors considered during the decision-making process.

Without the appropriate personnel who possess the necessary technical expertise and training, a contracting company must rely mostly on the salesperson's pitch and

\section{Seven Steps for Successful Contract Services}

Outsourcing is a growing trend among companies looking to incorporate specialized analytical services into product development and production. Here are some advantages of working with an equipment manufacturer for analytical testing services:

- Technology experts: Work with a team of experts who know the instrumentation.

- Cost analysis: Accurately define the projected costs of the applicable technology.

- Immediate results: Data collected during the contract can be used immediately.

- Build the case for purchase: Results obtained during the analytical testing period may form the basis of a proposal to purchase the equipment.

- Rationalize capital expenditures: Capital equipment purchase approvals can take months, but the process can be easier if proof-of-concept data are presented to decision makers.

- Lab design for in-house testing: Costs can be reduced by using the contracted service provider's lab design and layout when ready to bring the analytical testing in-house.

- Long-term relationship with contractor: Contracting company can build a strong relationship with its service provider and future equipment vendor. 
knowledge about the technology. Typical sales presentations include a long list of specifications, features, and benefits, but unless the end-user has the opportunity to test the equipment with representative samples over a period time, there are no guarantees that the selected equipment is the best choice for the project.

Selecting inadequate methods or buying the wrong equipment might lead to unsatisfactory results, longerthan-expected analysis times, unanswered questions, and a significant waste of time and money. Problems associated with selecting the wrong instrumentation can be prevented by using an equipment manufacturer with a trusted track record as a contract services provider.

\section{Evaluation Teams}

Evaluation teams are employees of the contracting company, usually engineers and technicians, who are led by a project manager. These individuals work directly with the contracted lab and are responsible for supplying the samples and materials to be tested, as well as providing feedback to test results. Comprehensive evaluation activities may take several months, but they provide companies with the advantage of pre-testing or conducting trial runs before a large investment of money and time is made. Once the evaluation team at the contracting company has a basic understanding of what the instrumentation in question is capable of and how it will solve their problems, an analytical services contract should be put in place.

\section{Extended Contracts}

In the event that the instrumentation in question is the right fit to solve a company's problem, extending the outsourcing period can minimize the need to invest in specialized capital equipment immediately. These savings are compounded by not having to pay for maintenance and/or calibration services and not sacrificing the floor space necessary to house the equipment and supplies.

During the extended contract phase, the contracted lab will use their trained personnel to develop and validate the necessary testing procedures (see Figure 3). Sample preparation, analysis parameters, data interpretation, and reporting will be optimized and converted into a turnkey solution that can be easily transferred to the contracting firm when appropriate (see Figure 4) [3].

\section{What About Quality?}

Regardless of the type of contract sought, every contracting company is responsible for diligence in evaluation of all possible analytical services providers, especially with regard to quality policies. Contracting companies must verify that their selected analytical services provider has a quality management system in place that adheres to the latest regulatory guidelines of the industry. Competent service providers will be able to generate quality scientific data using certified equipment and demonstrate that they are following standard operating procedures and validated methods.

\section{Conclusion}

An equipment manufacturer that has laboratory facilities and testing capabilities available for contract analytical services

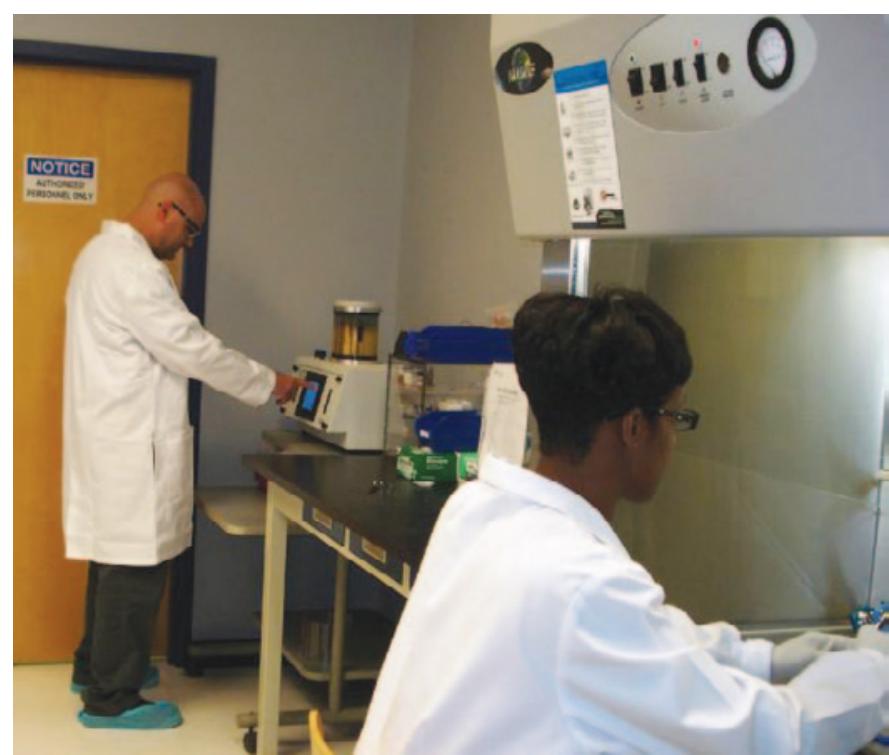

Figure 3: Analytical laboratory facilities co-located with equipment manufacturing companies. Team of analysts and laboratory technicians develop and optimize sample preparation procedures.

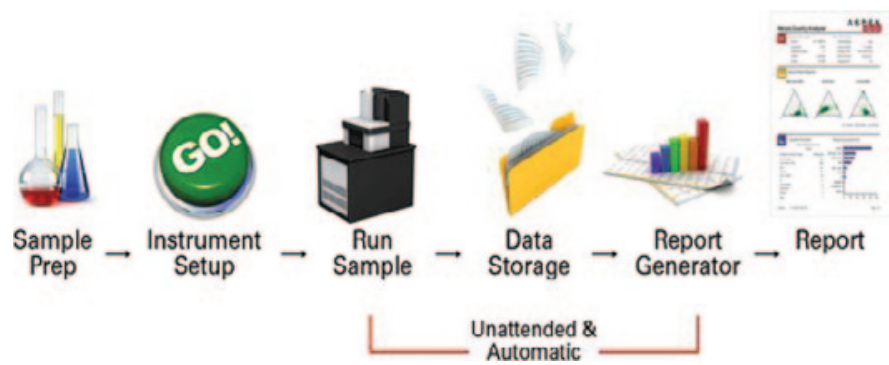

Figure 4: Overview of the steps taken during an extended contract phase that resulted in a turnkey solution for the customer. The contract laboratory was responsible for optimizing all the parameters for the preparation and the analysis of the samples. In addition, data mining and reporting activities were automated and customized based on the customers' requirements.

is the simple and logical choice for outsourcing analytical services. Whether the reason is time, money, or expertise, contracting these services gives companies an invaluable resource for completing analyses correctly and on time, as well as granting them an inside peak at instrumentation available for future purchase. An added benefit of outsourcing to an equipment manufacturer is the relationship that can be developed between the parties over time, which can turn into a lasting support system.

\section{References}

[1] DL Norwood, S Beale, NL DiGiulio, and R Fernando, Pharma Outsourcing 13(1) (2012), http://www. pharmoutsourcing.com/Featured-Articles/37645Analytical-Testing-Roundtable/.

[2] TC Kupiec, Pharma Outsourcing 5(1) (Jan. 2004) 107-109.

[3] FH Schamber and TJ Drake, Am Lab (Aug. 2011) 24-26. 